\title{
COMPETITIVE STRATEGIES OF PERSONNEL MANAGEMENT IN BUSINESS PROCESSES OF AGRICULTURAL ENTERPRISES FOCUSED ON DIGITALIZATION
}

\author{
Mykola Mykhailichenko', Olena Lozhachevska ${ }^{2}$, Volodymyr Smagin ${ }^{3}$, Olexander Krasnoshtan ${ }^{4}$, Mykola $^{2}$ \\ Zos-Kior5, *Iryna Hnatenko 6 \\ ${ }^{1}$ Assoc. Prof. PhD. National University of Life and Environmental Sciences of Ukraine. Heroyiv Oborony str. 15. 03041. Kyiv. \\ Ukraine. E-mail address: kadry2014@nubip.edu.ua
}

${ }^{2}$ Prof. Dr Sc. National Transport University. M. Omelyanovich-Pavlenko str.1. 01010. Kyiv. Ukraine.

E-mail address: o.lozhachevska@ntu.edu.ua

${ }^{3}$ Prof. Dr Sc. National Transport University. M. Omelyanovich-Pavlenko str.1. 01010. Kyiv. Ukraine.

E-mail address: vlsmagin50@gmail.com

${ }^{4}$ Assoc. Prof. PhD. National Transport University.M. Omelyanovich-Pavlenko str.1. O1010. Kyiv. Ukraine.

E-mail address: olexander.krasnoshtan@gmail.com

${ }^{5}$ Prof. Dr Sc. Poltava State Agrarian Academy. Skovoroda str. 1/3. 36003. Poltava. Ukraine.

E-mail address: zoskior@gmail.com

${ }^{6}$ Assoc. Prof. Dr Sc. Kyiv National University of Technologies and Design. Nemyrovycha-Danchenka str. 2. 01011. Kyiv. Ukraine. E-mail address: q17208@ukr.net

Received 2806 2020; Accepted 05082021

\begin{abstract}
In the context of globalization of the national economy, the agri-food sector as one of the leading business players faces a significant number of challenges, particularly the problem of ensuring the competitiveness of enterprises on both domestic and foreign markets. Implementation of management strategies aimed at the introduction of new technologies in business processes allows increasing the competitiveness of national agricultural enterprises based on digitalization. However, to succeed, it is necessary to provide an adequate personnel management strategy that meets the imperative of the integrated management strategy of the enterprise. Attention is drawn to personnel management strategies, which play an important role in the implementation of the motivational mechanism to achieve strategic goals through the effective realization of the labor potential of the agricultural enterprise. The key elements of any motivational mechanism are motivators, which are the factors of behavior and efficiency of personnel. Many theories describe the mechanisms of action of various motivators and their classifications, but the issues of using various motivators as key elements of the system of strategic personnel management at agri-food enterprises based on digitalization remain insufficiently studied. The purpose of the study is to conduct an analysis of the features of the application of personnel management strategies of agricultural enterprises focused on staff motivation, as well as to determine the level of influence of external and internal motivators on efficiency in agri-food enterprises based on digitalization. The research was conducted using a unique questionnaire to accumulate data. The methods of descriptive statistics were used to analyze the received data and to define the peculiarities of using the motivational mechanism in the agri-food industry. Regression analysis using an artificial neural network was performed to determine the impact of various motivators on productivity. The study has shown that national agricultural enterprises apply strategies based on motivational mechanisms that involve various motivators of both internal and external nature. However, the external motivators have been much better implemented, and above all salary as a key element of the motivational mechanism is used. At the same time, internal motivators are also important for the staff of agricultural enterprises. Therefore, the simultaneous use of external motivators and the development of internal motivators in competitive HR strategies are important.
\end{abstract}

Keywords: agricultural enterprises, business processe, competitiveness, digitalization, internal and external motivators, motivation, strategy.

JEL Codes: J28, J24.

Copyright (C) 2021 Author(s), published by Vytautas Magnus University. This is an open access article distributed under the terms of the Creative Commons Attribution Non-Commercial 4.0 (CC BY-NC 4.0) license, which permits unrestricted use, distribution, and reproduction in any medium provided the original author and source are credited. The material cannot be used for commercial purposes. 


\section{Introduction}

Under the conditions of the acceleration of the innovative transformation of the agri-food sector, which affects the functioning of all players in the sector, and most of all agricultural enterprises, the creation of a highly efficient and adaptive management system of agricultural enterprises becomes a relevant task. The development and implementation of innovative technologies in the business processes of the enterprise prompted the transition to a strategic approach to management, which was implemented in the form of transformation of management structures, changing management methods and styles, increasing the role of creative work and synergies from various components of enterprise management. The formation of an integrated management system is largely taking into account the need to respond quickly to input signals coming from the external functional environment in the form of threats, challenges, and new opportunities. It is strategic management that aims at achieving the long-term goals and mission of the enterprise. In the process of implementing the management strategy, there is an adequate adaptation of all components of the integrated management system of the agricultural enterprise in accordance with its goals. In the context of the implementation of innovative technologies and processes, there is a rapid increase in the impact of labor potential on the competitiveness of the agricultural enterprise, which affects the ability of the enterprise to withstand competition and achieve success in turn. It tremendously depends on the quality of the personnel management subsystem that determines whether an agricultural enterprise will be able to adapt to fluctuations in the business environment, realize its potential, ensure sustainable development and win the competition.

The strategy of personnel management is a key element of the integrated management system of an agricultural enterprise, which operates in conditions of significant market volatility and increased competition among agricultural enterprises. The strategy creates the basis for identifying critical factors that affect the success of the enterprise, in turn, strategic decisions are made to have a long-term impact on the prospects of the agricultural enterprise. The competitive strategy of personnel management is a set of planned measures of implementing the concept of labor potential of an agricultural enterprise, its development, and effective realization, which are long-term and aimed at ensuring the competitive advantages of the agricultural enterprise. This goal is achieved through the development and implementation of personnel management measures that create and maintain personnel loyalty, ensure the development and put into practice an effective motivational mechanism, implement an adaptive system of selection, recruitment, and adaptation of staff, create a system of unique and adequate competencies, organize performance appraisal, corporate culture, etc. Any strategy of personnel management provides long-term planning and design of actions based on the integrated strategy of use of the enterprise potential; synchronization of personnel management measures and a certain set of innovative business processes; introduction of measures that allow achieving certain competitive advantages through the realization of the labor potential of the enterprise.

In the functional dimension, the personnel management strategy looks like a set of the following components: strategic selection of personnel; strategic personnel development; strategic personnel appraisal; strategic motivation, as well as a mechanism for assessing the effectiveness of strategy implementation. These components are formed under the strategic imperative, which can be strategically vital for the company target. Changing the imperative inevitably causes changes in the elements of strategy and their relationships. 
Management Theory and Studies for Rural Business and Infrastructure Development

eISSN 2345-0355. 2021. Vol. 43. No. 3: 403-414

Article DOI: https://doi.org/10.15544/mts.2021.37

Strategies in a turbulent environment and uncertainty are constantly being transformed and have no clear boundaries. Thus, according to Mintzberg (2009), a strategy is a response to the constant change of the situation in the form of future-oriented measures and is implemented through adaptive actions and responses to changes and challenges. The impact of digitalization on motivational strategies becomes particularly important today.

Motivational strategy is a component of personnel management strategy and is aimed at forming and implementing a system of personnel motivation, which helps to achieve the strategic goals of an agricultural enterprise.

The aim of the study is to conduct an analysis of the features of personnel management strategies of agricultural enterprises focused on personnel motivation, as well as to determine the level of influence of external and internal motivators on labor efficiency in agri-food enterprises based on digitalization.

Accordingly, a survey of employees of several agricultural enterprises was conducted using a unique questionnaire. For the purpose of the survey, 1467 questionnaires were distributed among employees, 1275 of which were filled in correctly and used for the analysis. The use of statistical methods allowed us to analyze the features of the application of the motivational mechanism in the agri-food sphere. An artificial neural network was used to create the regression model, which allowed us to study the impact of motivators on the productivity of agricultural personnel.

The analysis shows that agri-food enterprises use strategies that involve a motivational mechanism focused on measures aimed at eliminating hygiene factors or on the application of external motivators, and pays much less attention to the application of internal motivators. However, some internal motivators have a significant impact on productivity. Namely, in the context of personnel management practice, improving the efficiency of the usage of internal motivators is a reserve for increasing the efficiency and competitiveness of agricultural enterprises, including based on digitalization.

The analysis of the scientific literature shows that a significant number of researchers have paid attention to the study of various aspects of personnel motivation: motivational theories, a set of motivators and demotivators, salary as a motivator, and many others.

The perception of motivation as a system based on the principles of assessment and ranking of specific attributes of the work process has been shaped by many studies on personnel motivation. And as noted in their work Kovach (1995), Clark and Pia DiPaola (2010) it is realized through the use of internal and external stimuli. Many scientific papers have been devoted to the study of motivational factors and the development of theories of motivation. The most famous motivational theory is the theory developed by Maslow (1970). In his research, Maslow A. pays attention to the psychological aspects of motivation, analyzes the components and hierarchical structure of human needs, and emphasizes the importance of self-actualization as a factor of motivation. Deci and Ryan (2015) also made a significant contribution to the development of motivational theories by developing a theory of self-determination that assumes three basic psychological needs, namely competence, autonomy, and relatedness.

Herzberg (1968) and later Jurgensen (1978) and Manolopoulos (2007) studied the two types of factors. It should be noted that this theory has been one of the most influential among motivational theories over the last decade.

Pupavac (2015) analyzes the relevance and validity of Herzberg's theory based on data obtained from employees of non-profit organizations and proves that the theory remains quite valid and can be used in practice. 
Many researchers have paid attention to the study of sectoral peculiarities of the implementation of various motivational strategies. For example, Shaaban (2017) explores the relationship between the management style used by management and the degree to which organizational goals are achieved in public administration. Conrad et al. (2015) investigate the features of motivation in the field of health care, namely, identify the most important motivators among physicians, which are occupational safety and the interesting nature of work. Manolopoulos (2007) and Koronios et al. (2017) conduct a thorough analysis of the relationship between work motivation and the efficiency of public sector enterprises. Kharchenko (2021) analyzes the peculiarities of the application of motivational strategy in a large financial company and explores the variety of motivational profiles that characterize the managers and employees working with clients. However, despite the large number of scientific papers examining various aspects of motivation, the peculiarities of the application of motivational strategies in agri-food enterprises remain insufficiently covered and need attention from scientists.

\section{Research results and discussion}

Examining the motivation of agricultural personnel, 14 motivators were selected, which can be divided according to the classical theory of Herzberg (1968) into hygienic factors or external motivators, such as salary, safety and working conditions, personnel policy and others, and internal factors or internal motivators such as achievements, recognition in accordance with achievements, work itself, responsibility, promotion, and professional growth. The following motivators were studied in the research: salary and remuneration system (M1), company management policy (M2), occupational safety (M3), labor control system (M4), the level of interaction and communication of subordinates and managers (M5), the microclimate in the team (M6), working conditions (M7), external selfactualization (M8), recognition (M9), professional development (M10), achievements (M11), nature of work (M12), career promotion (M13), the level of responsibility (M14). The classification of motivators, their reflection in the questionnaire, and the measurement scale are given in table 1 . The 5-point Likert scale was used in the survey, where 1 - strongly disagree, 2 - disagree, 3 - largely, 4 - agree, 5 - strongly agree.

A sample of five agri-food enterprises was selected for the analysis of internal and external motivators. However, companies differ in size and specificity of business processes, which helped to avoid the deformation of the analysis due to any bias. The analytical study was conducted using the information obtained through a unique questionnaire developed for the current survey. 


\section{Table 1. Classification of the motivators, their reflection in the questionnaire, and measurement scale}

\begin{tabular}{|c|c|c|c|c|c|}
\hline \multirow{2}{*}{ 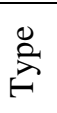 } & \multirow{2}{*}{ Motivational tool } & \multirow{2}{*}{ Variable } & \multirow{2}{*}{ Questions in the questionnaire } & \multicolumn{2}{|c|}{ Scale } \\
\hline & & & & Highest & Lowest \\
\hline \multirow{7}{*}{ 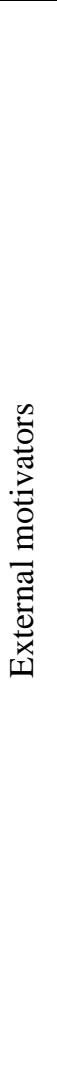 } & $\begin{array}{l}\text { Salary and } \\
\text { remuneration } \\
\text { system }\end{array}$ & M1 & $\begin{array}{c}\text { The company uses a fair, transparent, and understandable } \\
\text { remuneration system. I receive a decent salary, which takes } \\
\text { into account my contribution, my level of education, } \\
\text { previous experience, and level of professionalism. }\end{array}$ & 5 & 1 \\
\hline & $\begin{array}{c}\text { Company } \\
\text { management } \\
\text { policy }\end{array}$ & M2 & $\begin{array}{c}\text { The company uses clear and adequate management } \\
\text { practices. }\end{array}$ & 5 & 1 \\
\hline & $\begin{array}{l}\text { Occupational } \\
\text { safety }\end{array}$ & M3 & $\begin{array}{c}\text { The company provides a working environment that is safe } \\
\text { for employees and takes into account all occupational } \\
\text { safety standards. }\end{array}$ & 5 & 1 \\
\hline & $\begin{array}{c}\text { Labor control } \\
\text { system }\end{array}$ & M4 & The company uses an effective and clear control system. & 5 & 1 \\
\hline & $\begin{array}{c}\text { The level of } \\
\text { interaction and } \\
\text { communication of } \\
\text { subordinates and } \\
\text { managers }\end{array}$ & M5 & $\begin{array}{l}\text { The company has implemented measures to ensure } \\
\text { effective communication and interaction of subordinates } \\
\text { and managers. }\end{array}$ & 5 & 1 \\
\hline & $\begin{array}{l}\text { The microclimate } \\
\text { in the team }\end{array}$ & M6 & $\begin{array}{c}\text { The company creates a working environment that provides } \\
\text { effective communication and collaboration of employees } \\
\text { in all areas, including a friendly atmosphere, which allows } \\
\text { sharing experience and knowledge as effectively as } \\
\text { possible. }\end{array}$ & 5 & 1 \\
\hline & $\begin{array}{l}\text { Working } \\
\text { conditions }\end{array}$ & M7 & $\begin{array}{c}\text { The company provides a working environment with } \\
\text { modern equipment, innovative technologies, developed } \\
\text { infrastructure, etc. }\end{array}$ & 5 & 1 \\
\hline \multirow{7}{*}{ 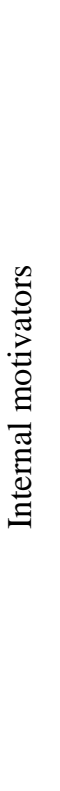 } & $\begin{array}{l}\text { External self- } \\
\text { actualization }\end{array}$ & M8 & $\begin{array}{c}\text { The company provides freedom of decision-making on } \\
\text { methods and approaches to performing professional duties } \\
\text { within my competence and encourages initiative. }\end{array}$ & 5 & 1 \\
\hline & Recognition & M9 & $\begin{array}{c}\text { The company uses a transparent, fair, and clear system of } \\
\text { indicators that reflects the effectiveness and quality of my } \\
\text { work. }\end{array}$ & 5 & 1 \\
\hline & $\begin{array}{l}\text { Professional } \\
\text { development }\end{array}$ & M10 & $\begin{array}{l}\text { My work requires continuous training and skill } \\
\text { enhancement. The company supports the concept of } \\
\text { "lifelong learning" and encourages participation in } \\
\text { seminars, conferences, workshops. }\end{array}$ & 5 & 1 \\
\hline & Achievements & M11 & $\begin{array}{l}\text { My work is important and allows me to create something } \\
\text { meaningful for society. }\end{array}$ & 5 & 1 \\
\hline & Nature of work & M12 & My work is creative and interesting. & 5 & 1 \\
\hline & Career promotion & M13 & $\begin{array}{c}\text { The company has created a transparent, fair, and clear } \\
\text { system of indicators based on which employees are } \\
\text { promoted. }\end{array}$ & 5 & 1 \\
\hline & $\begin{array}{l}\text { Level of } \\
\text { responsibility }\end{array}$ & M14 & The company provides an adequate level of responsibility & 5 & 1 \\
\hline
\end{tabular}


The study was conducted with the involvement of the personnel of five agri-food enterprises in different regions of Ukraine, namely: PE "Agroprogress" (hereinafter F1), PSP "Slobozhanshchina Agro" (F2), LLC "AgroKim" (F3), LLC "Burat" (F4 ), LLC "Chernihiv Industrial Dairy Company" (F5).

In order to conduct the survey, 1469 questionnaires were distributed among the personnel of these enterprises, and 1275 were received back, which is approximately $87 \%$ of the level of responses. In the gender dimension, the respondents were distributed as follows: the proportion of men $75 \%$ and the proportion of women $25 \%$, respectively. In the functional dimension, the respondents were divided into production and administrative staff and accounted for $68 \%$ and $32 \%$, respectively. General information about the survey is given in table 2 .

Table 2. General information about the survey of enterprises

\begin{tabular}{|c|c|c|c|c|c|c|c|}
\hline \multirow{2}{*}{ Company } & \multirow{2}{*}{$\begin{array}{c}\text { Number of } \\
\text { distributed } \\
\text { questionnaires }\end{array}$} & $\begin{array}{c}\text { Number of } \\
\text { received } \\
\text { questionnaires } \\
\text { with answers }\end{array}$ & \multirow{2}{*}{$\begin{array}{c}\text { Level of } \\
\text { answers, \% }\end{array}$} & \multicolumn{2}{|c|}{$\begin{array}{c}\text { Gender } \\
\text { dimension }\end{array}$} & \multicolumn{2}{|c|}{ Functional dimension } \\
\hline F1 & 342 & 310 & 91 & 0.77 & 0.23 & 0.73 & 0.27 \\
\hline F2 & 263 & 255 & 97 & 0.78 & 0.22 & 0.68 & 0.32 \\
\hline F3 & 370 & 311 & 84 & 0.75 & 0.25 & 0.74 & 0.26 \\
\hline F4 & 60 & 53 & 88 & 0.63 & 0.37 & 0.82 & 0.18 \\
\hline F5 & 434 & 346 & 80 & 0.74 & 0.26 & 0.56 & 0.44 \\
\hline Total & 1469 & 1275 & 87 & 0.75 & 0.25 & 0.68 & 0.32 \\
\hline
\end{tabular}

The Cronbach's alpha coefficient with splitting into 2 subgroups is used to assess the reliability of the questionnaire. This coefficient is a generally accepted index of reliability, which is calculated by the formula (1):

$$
\alpha=\frac{k}{k-1} \cdot\left(1-\frac{\sum_{i=1}^{k} s_{i}^{2}}{s_{\mathrm{e}}^{2}}\right)
$$

where $\mathrm{k}-$ number of individual positions,

$$
\begin{aligned}
& s_{i}^{2}-\text { variance for the } i \text {-th position, } \\
& s_{e}^{2}-\text { variance for the sum of all positions. }
\end{aligned}
$$

For the developed questionnaire Cronbach's alpha is equal to: for the full scale 0.85 , for the group of internal motivators 0.84 , for the group of external motivators 0.95 . Also, $t$ $=7.89$ at a significance level of 0.0001. Such values of the coefficients allow claiming that the developed questionnaire technique is reliable.

An artificial neural network is used to study the impact of individual motivators on performance as it allows to build a multiple nonlinear regression model that reflects the relevant patterns. Modeling with the neural network helps to analyze large amounts of data obtained through the survey, to identify new correlations and stable internal patterns, as well as to avoid the limitations that arise during traditional multiple regression analysis. The obtained model allows developing and implementing motivational measures that will increase the effectiveness of management strategy by increasing the efficiency of the application of labor potential.

The neural network belongs to the multilayer perceptron type, which has a threelayer architecture that provides input, hidden, and output layers of neurons. The input layer includes 14 neurons $N_{i}(i \in \overline{1,14})$, each of which corresponds to a separate motivator under study. The inner hidden layer has 2 neurons $H_{j}(j \in \overline{1,2})$. The output layer has 1 neuron $Y$, 


\section{sciendo}

Management Theory and Studies for Rural Business and Infrastructure Development

eISSN 2345-0355. 2021. Vol. 43. No. 3: 403-414

Article DOI: https://doi.org/10.15544/mts.2021.37

which represents the resulting indicator and corresponds to the productivity index. Each neuron of the hidden layer $H_{j}$ has a connection with each of the 14 neurons $N_{i}$ on the input layer. For each such connection, the value of the so-called weight $\omega_{j i}$ is determined, which characterizes the importance of the connection. The greater the value of the weight $\omega_{j i}$, the more significant the connection, the greater the degree of dependence of the neuron of the hidden layer $H_{j}$ on the neuron of the input layer $N_{i}$. A low value of $\omega_{j i}$, on the other hand, indicates that the neuron of the hidden layer $H_{j}$ is slightly dependent on the neuron $N_{i}$ on the input layer. The neuron of the output layer has a connection with each of the neurons of the hidden layer. The characteristic of the connection between the neurons of the hidden layer $H_{j}$ and the neuron of the output layer $Y$ is the weight $\Omega_{j}$. The general architecture of the neural network is shown in figure 1.

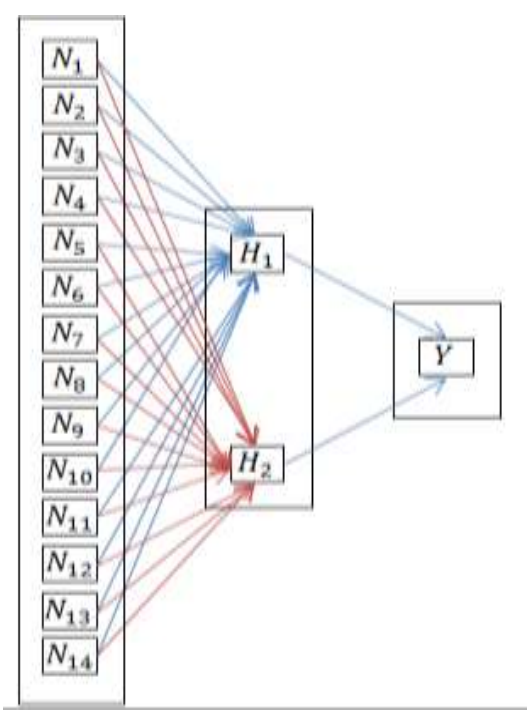

Figure 1. The general architecture of the neural network

The general mathematical description of the architecture of the constructed neural network can be represented in the form of the following formula (2):

$Y=\sum_{j=1}^{2}\left(\Omega_{j} \cdot f\left(\sum_{i=1}^{14}\left(\omega_{j i} \cdot \varepsilon_{i}\right)+b_{j}\right)\right)+b$

where $\mathrm{i}$ - the number of neurons in the input layer,

$\mathrm{j}$ - the number of neurons on the hidden layer,

$\Omega_{\mathrm{j}}$ - the weight for the connection between the neuron $H_{j}$ on the hidden layer and the neuron $Y$ on the output layer, $\mathrm{f}-$ the activation function,

$\omega_{\mathrm{ji}}$ - the weight for the connection between the neuron $N_{i}$ on the input layer and the neuron $H_{j}$ on the hidden layer,

$\varepsilon_{\mathrm{i}}-$ value at the input layer,

$b_{j}$ - the shift of neurons on the input layer to the corresponding neuron of the hidden layer $H_{j}, \mathrm{~b}$ - the shift of neurons on the hidden layer to the neuron of the output layer $Y$.

A logistic function was used to activate hidden and output neurons.

That neural network has helped to build the model that allows analyzing the impact of external and internal motivators on personnel 
productivity. The created model was the result of neural network training, which took place on the basis of data obtained through the survey using the BFGS learning algorithm. The network was trained until the sum of the error squares reached below 0.001 and was 0.0006 . The correlation coefficient is 0.969 .

The weights that characterize the relationship between the neurons of the input layer and the neurons of the hidden layer $\omega_{j i}$ were calculated during the construction of the model and are shown in table 3.

Table 3. Weighting factors $\omega_{j i}$ for latent layer neurons $H_{1}$ and $H_{2}$

\begin{tabular}{|c|c|c|c|}
\hline \multicolumn{2}{|c|}{ Weights $\boldsymbol{\omega}_{\mathbf{i j}}$ for neurons on the hidden layer } \\
\hline \multicolumn{2}{|c|}{$H_{1}$} & \multicolumn{2}{|c|}{$H_{2}$} \\
\hline$\omega_{11}$ & -1.4652 & $\omega_{21}$ & 0.2605 \\
\hline$\omega_{12}$ & 0.0225 & $\omega_{22}$ & 0.1956 \\
\hline$\omega_{13}$ & 1.7124 & $\omega_{23}$ & 0.0800 \\
\hline$\omega_{14}$ & 1.9403 & $\omega_{24}$ & 0.2215 \\
\hline$\omega_{15}$ & -0.3338 & $\omega_{25}$ & 0.1425 \\
\hline$\omega_{16}$ & -1.2378 & $\omega_{26}$ & 0.3798 \\
\hline$\omega_{17}$ & 5.4924 & $\omega_{27}$ & 0.1276 \\
\hline$\omega_{18}$ & 1.6938 & $\omega_{28}$ & 0.1259 \\
\hline$\omega_{19}$ & 1.1586 & $\omega_{29}$ & 0.2976 \\
\hline$\omega_{110}$ & 0.5412 & $\omega_{210}$ & 0.1812 \\
\hline$\omega_{111}$ & 0.6497 & $\omega_{211}$ & 0.1189 \\
\hline$\omega_{112}$ & 0.1420 & $\omega_{212}$ & 0.2705 \\
\hline$\omega_{113}$ & 0.4527 & $\omega_{213}$ & 0.1619 \\
\hline$\omega_{114}$ & 0.6826 & $\omega_{214}$ & 0.2242 \\
\hline
\end{tabular}

The weights that characterize the relationship between the neurons of the hidden layer and the neurons of the output layer $\Omega_{j}$ are shown in table 4 . The hidden neurons $H_{1}$ and
$H_{2}$, respectively, have hidden shifts -10.1617 and -0.3402 . The shift of the resulting function is -6.5913 .

\section{Table 4. Weights for the neuron of the output layer}

\begin{tabular}{|c|c|}
\hline $\begin{array}{l}\text { Weights } \boldsymbol{\Omega}_{\boldsymbol{j}} \text { for the neuron of the } \\
\text { output layer } \boldsymbol{Y}\end{array}$ \\
\hline$\Omega_{1}$ & 4.7115 \\
\hline$\Omega_{2}$ & 9.2192 \\
\hline
\end{tabular}

As mentioned earlier, the survey helped to obtain the data, the analysis of which reveals the peculiarities of the application of personnel motivation in the system of strategic management of business processes of agricultural enterprises. The average values of the responses obtained by enterprises are shown in table 5. 
Management Theory and Studies for Rural Business and Infrastructure Development

eISSN 2345-0355. 2021. Vol. 43. No. 3: 403-414

Article DOI: https://doi.org/10.15544/mts.2021.37

Table 5. Survey results: average values of answers by enterprises

\begin{tabular}{|l|c|c|c|c|c|c|}
\hline \multirow{2}{*}{ Motivators } & \multicolumn{5}{|c|}{ Company } \\
\cline { 2 - 7 } & F1 & F2 & F3 & F4 & F5 & Average \\
\hline M1 & 3.43 & 3.26 & 3.48 & 3.13 & 3.42 & 3.34 \\
\hline M2 & 3.00 & 2.75 & 2.97 & 2.66 & 2.93 & 2.86 \\
\hline M3 & 2.46 & 2.88 & 3.12 & 2.74 & 3.07 & 2.85 \\
\hline M4 & 2.66 & 3.01 & 3.24 & 2.89 & 3.27 & 3.02 \\
\hline M5 & 2.7 & 3.07 & 3.28 & 2.96 & 3.24 & 3.05 \\
\hline M6 & 2.87 & 3.16 & 3.33 & 2.98 & 3.29 & 3.13 \\
\hline M7 & 2.77 & 3.18 & 3.34 & 2.98 & 3.28 & 3.11 \\
\hline M8 & 2.66 & 2.35 & 2.71 & 2.68 & 2.73 & 2.63 \\
\hline M9 & 2.59 & 2.31 & 2.63 & 2.64 & 2.68 & 2.57 \\
\hline M10 & 2.53 & 2.27 & 2.58 & 2.6 & 2.65 & 2.53 \\
\hline M11 & 2.6 & 2.44 & 2.58 & 2.68 & 2.7 & 2.6 \\
\hline M12 & 2.66 & 2.35 & 2.7 & 2.74 & 2.76 & 2.64 \\
\hline M13 & 2.85 & 2.54 & 2.91 & 2.98 & 2.95 & 2.85 \\
\hline M14 & 2.58 & 2.91 & 2.52 & 2.6 & 2.77 & 2.68 \\
\hline
\end{tabular}

The data indicate that the external motivators are dominant for all of the enterprises, for which the average value of responses is 3.09, and for the group of the internal motivators this indicator is 2.64 . The highest total level of answers is registered at F5 and is equal to 41.76 , in other words, according to employees, motivational tools are used more efficiently than at the other companies. The lowest total level is observed at F1, where it is 38.35. It means that the employees of this enterprise are much less motivated than the employees of the other agricultural enterprises that took part in the survey. The highest indicator is the perception of fairness and adequacy of the remuneration system, for which the average value is 3.34. The highest rate of M1 was registered at F3 and the lowest - at enterprise F4. Also, the following external motivators are of great importance: the microclimate in the team and working conditions, for which the average values of responses are 3.13 and 3.11, respectively. The maximum value of M6 is registered at enterprise F5, and the maximum value of M7 is registered at enterprise F3. Among external motivators, the lowest values were given to the safety of the working environment and management policy of a company, for which the average values are 2.85 and 2.86, respectively. The lowest value of M3 is observed at enterprise F1, and the lowest value of M2 - at enterprise F4 and equal to 2.46 and 2.66 , respectively.

The data analysis indicates that the use of internal motivators as components of the motivational mechanism of the strategic personnel management system is much less developed because the average value of responses is 2.64. The highest importance among the internal motivators was given to career opportunity and adequate level of responsibility and are 2.85 and 2.68 respectively. The M13 tool is best used at F4 and is 2.98, and the M14 tool is at F2 at 2.92. The lowest scores 
among the internal motivators were given to the following motivators: the possibility of professional development and recognition, the average values of which are 2.53 and 2.57 respectively. The lowest levels of M10 and M9 are registered at $\mathrm{F} 2$ and equal to 2.27 and 2.31 respectively.

The conclusion from the above is that national agri-food enterprises, implementing personnel management strategies, prefer the use of external motivators, namely: salary, working conditions, and microclimate in the team. F2 and F3 have a significant difference between the use of groups of motivators in favor of external, F5 has a moderate difference, and F1 and F4 implement personnel management strategies that have less difference between the use of external and internal motivators, but still assume the dominance of external motivators in the strategy.

It is also advisable to explore which motivators have the greatest impact on productivity because it is due to its growth that the company can achieve strategic goals. For this purpose, regression analysis was performed using an artificial neural network. The study indicates that the neuron with the greatest influence on $H_{1}$ is the motivator M7 - working conditions, which has the greatest weight $\omega_{17}=$ 5.4924 compared to the other weights. labor control, occupational safety, and external selfactualization with the following values of the weights 1.9403, 1.7124, and 1.6938 respectively. And M2 - the company's policy in the field of management affects to a small extent, for which $\omega_{12}$ equals to 0.0225 . $H_{2}$ is most influenced by M6, M9, and M12, namely, the microclimate in the team, recognition and nature of work, with values of the weights 0.3798 , 0.2976 , and 0.2705 respectively. The least influential on the neuron $\mathrm{H}_{2}$ is the neuron corresponding to the motivator M3 with the weight of 0.08. The influence of the neurons of the hidden layer on the neuron of the output layer is characterized by weights $\Omega_{1}=4.7115$ and $\Omega_{2}$ $=9.2192$, ie neuron $H_{2}$ affects much more.

The regression model also allows predicting possible changes in labor productivity by increasing the efficiency of individual tools of motivation. For example, an increase of M7 (working conditions) by one point could increase productivity by about $4.86 \%$, an increase of M9 (recognition) - 3.10\%, an increase of M6 (microclimate in the team) $-3.02 \%$, an increase of M12 (nature of work) - 2.48\%. The lowest result in productivity growth of only $1.19 \%$ was obtained due to the growth of the M5 score (level of interaction and communication). As the analysis shows, the impact of M1 (salary and remuneration system) is moderate and if it increases by one point, the agri-food enterprise will receive an increase in labor productivity by about $1.94 \%$.

Based on the above, it is possible to rank the motivators by the level of impact on productivity (R2) and the level of their implementation in the enterprises in accordance with the assessments of employees (R1). The ranking results are shown in table 6 . 


\section{sciendo}

Management Theory and Studies for Rural Business and Infrastructure Development

eISSN 2345-0355. 2021. Vol. 43. No. 3: 403-414

Article DOI: https://doi.org/10.15544/mts.2021.37

Table 6. Ranking of motivators by the level of their implementation (R1) and by the level of impact on productivity (R2)

\begin{tabular}{|l|c|c|l|}
\hline \multicolumn{1}{|c|}{ Motivator } & R1 & R2 & Conditions \\
\hline M1 & 1 & 8 & R1> R2 \\
\hline M2 & 6 & 7 & R1>R2 \\
\hline M3 & 7 & 13 & R1> R2 \\
\hline M4 & 5 & 5 & R1= R2 \\
\hline M5 & 4 & 14 & R1> R2 \\
\hline M6 & 2 & 3 & R1<R2 \\
\hline M7 & 3 & 1 & R1>R2 \\
\hline M8 & 11 & 9 & R1> R2 \\
\hline M9 & 13 & 2 & R1> R2 \\
\hline M10 & 14 & 10 & R1>R2 \\
\hline M11 & 12 & 11 & R1>R2 \\
\hline M12 & 10 & 6 & R1>R2 \\
\hline M13 & 8 & 12 & R1<R2 \\
\hline M14 & 9 & 4 & R1>R2 \\
\hline
\end{tabular}

Under the condition R1> R2 there is an imbalance between the level of significance of the motivator for employees and the level of its implementation in the enterprise, so there is a need to implement measures that will implement this motivator in personnel management strategy more effectively. If $\mathrm{R} 1=\mathrm{R} 2$ there is no imbalance. Under the condition $\mathrm{R} 1<\mathrm{R} 2$ there is an inverse situation, but the development of any measures requires additional analysis because reducing the effectiveness of the motivator can lead to demotivation of personnel.

\section{Conclusions}

The growing role of the agri-food sector in ensuring national security is relevant to the study of management strategies of agricultural enterprises to increase their efficiency and competitiveness in both domestic and foreign markets. In the context of the implementation of digitalization technologies and business processes in the practice of national agricultural enterprises, it is important to adapt, develop and implement adequate personnel management strategies that meet the requirements of integrated management strategies of agricultural enterprises focused on digitalization. It brings up the problem of staff motivation of agricultural enterprises, including the development and implementation of a personnel management strategy that focuses on the use of effective methods of personnel motivation particularly acute. It is through the implementation of such a strategy that the agricultural enterprise is able to effectively realize its labor potential, which is one of the key elements in achieving competitive advantages and long-term goals of the enterprise through the successful implementation of innovative business processes.

The study shows that national agri-food enterprises use a variety of motivators in their human resource management strategies, both of internal and external genesis, but the external motivators are more developed and used much wider. The most popular among the external motivators are: salary and remuneration system, the microclimate in the team and working conditions, at the same time, the least developed among the external tools are: safety of the working environment and management policy of the company.

However, analyzing the use of the internal motivators, it becomes obvious that such tools are used much less. For example, the most developed tool among the internal motivators is 
the opportunity for career growth and an adequate level of responsibility, and the least implemented is the recognition and opportunity for professional development.

According to the analysis, the internal motivators are of great importance for the personnel of agricultural enterprises and can be considered as a reserve for improving the effectiveness of management strategies.
Particular attention should be paid to the additional implementation of measures aimed at increasing the level of recognition of employees and ensuring an adequate level of personnel responsibility.

It is important to provide the permanent monitoring of employee satisfaction and a flexible motivational mechanism that can adapt to changes and apply appropriate motivators.

\section{References}

Clark, Pia DiPaola. (2010). "Employee Motivation Factors: A Reexamination of Kovach's Study 10 Years Later" Business Masters. Paper 1.

Conrad, D., Ghosh, A \& Isaacson, M. (2015), "Employee motivation factors: A comparative study of the perceptions between physicians and physician leaders", International Journal of Public Leadership, Vol. 11 No. 2, 92-106.

Deci E., Ryan R. (2015) Self-Determination Theory James D. Wright, International Encyclopedia of the Social \& Behavioral Sciences (Second Edition), Elsevier, 486-491.

Herzberg, F. (1968) One More Time: How Do You Motivate Employees? Harvard Business Review, 46, 53-62. 276.

Jurgensen, C. (1978). Job preferences (What makes a job good or bad?). Journal of Applied Psychology, 63(3), 267-

Koronios, K., Mavromati, M., Kriemadis, A. (2017). Motivating public sector employees: Evidence from Greece, International Journal of Business and Economic Sciences Applied Research (IJBESAR), ISSN 2408-0101, Eastern Macedonia and Thrace Institute of Technology, Kavala, Vol. 10, Iss. 1, 7-12

Kovach, K. (1995). Employee motivation: Addressing a crucial factor in your organization's performance. Employment Relations Today. 93-107.

Kharchenko, V. (2021). Motivation and Motivation Profiles of the Employees in a Modern Organization. Sociologicheskaja nauka i social'naja praktika. 9. 156-171.

Manolopoulos, D. (2007). 'An evaluation of employee motivation in the extended public sector in Greece', Employee Relations, 30, 1, 63-85.

Maslow, A. (1970). Motivation and personality. New York: Harper \& Row.

Mintzberg, H., Ahlstrand, B \& Lampel, J. (2009). Strategy safari: The complete guide through the wilds of strategic management. Harlow: Pearson Prentice Hall.

Pupavac, D. (2015). The Ghost Of Herzberg Motivational Theory: Motivators And Demotivators. International Journal Vallis Aurea.

Shaaban, S. (2017). The Impact of Leadership Style on Middle Managers' Motivation: A Study of the Ministry of Civil Aviation in Egypt. Journal of Business and Management Sciences. 5(3):100-107 